\title{
Correction to: Reducing ammonia emission by aluminum sulfate addition in litter and its influence on productive, reproductive, and physiological parameters of dual-purpose breeding hens
}

\author{
Youssef A. Attia ${ }^{1}$. Fulvia Bovera ${ }^{2} \cdot$ Reda A. Hassan ${ }^{3}$ Ebtehal A. Hassan ${ }^{3} \cdot K_{\text {Khalil M. Attia }}^{3} \cdot$ Mohamed H. Assar $^{4}$. \\ Fouad Tawfeek ${ }^{4}$
}

Published online: 19 January 2022

๑) Springer-Verlag GmbH Germany, part of Springer Nature 2022

\section{Correction to: Environmental Science and Pollution Research https://doi.org/10.1007/s11356-021-17613-0}

Table 1 layout is corrected in the original paper and the correct Funding number should be FP-218-42 H.

The Original article has been corrected.

Publisher's note Springer Nature remains neutral with regard to jurisdictional claims in published maps and institutional affiliations.

The original article can be found online at https://doi.org/10.1007/ s11356-021-17613-0.

Youssef A. Attia

yaattia@kau.edu.sa

$\triangle$ Fulvia Bovera

bovera@unina.it

Reda A. Hassan

redaalihasan@yahoo.com

1 Agriculture Department, Faculty of Environmental Sciences, King Abdulaziz University, PO Box 80208, Jeddah 21589,

Saudi Arabia

2 Department of Veterinary Medicine and Animal Production, University of Napoli Federico II, via F. Delpino,1, 80137 Napoli, Italy

3 Department of Poultry Nutrition, Animal Production Research Institute, Agricultural Center, Dokki, Giza, Egypt

4 Department of Poultry Breeding, Animal Production Research Institute, Agricultural Center, Dokki, Giza, Egypt 